\title{
A Sustainable Plan to Rescue HR from Itself
}

\author{
James W. Westerman (ID
}

check for

updates

Citation: Westerman, J.W. A Sustainable Plan to Rescue HR from Itself. Sustainability 2021, 13, 7587.

https://doi.org/10.3390/su13147587

Academic Editors: Won-Moo Hur and Yuhyung Shin

Received: 10 May 2021

Accepted: 30 June 2021

Published: 7 July 2021

Publisher's Note: MDPI stays neutral with regard to jurisdictional claims in published maps and institutional affiliations.

Copyright: (C) 2021 by the author Licensee MDPI, Basel, Switzerland This article is an open access article distributed under the terms and conditions of the Creative Commons Attribution (CC BY) license (https:// creativecommons.org/licenses/by/ $4.0 /)$.
Department of Management, Appalachian State University, Boone, NC 28608, USA; westermanjw@appstate.edu

\begin{abstract}
The Human Resource (HR) function is often viewed by those in organizations as a process function and a cost-center, which results in an enhanced risk of outsourcing and automation. However, HR is also uniquely positioned to engage firms in cross-functional transformational change efforts, as its work is embedded in every business function within an organization. Sustainable HR and the triple bottom line (TBL) present opportunities for HR to build a strategic role within organizations. This essay provides strategic and tactical models, with specific steps for implementation, to assist HR in re-assert its role in driving the competitiveness of the firm through Sustainable HR.
\end{abstract}

Keywords: human resource management; sustainable HR; green HR; strategic HR; sustainability; social justice; diversity; environment; SDGs; triple bottom line

Nearly a third (27\%) of Human Resource (HR) leaders in a recent survey reported that they are cutting HR services and processes [1]. HR has been on the COVID-19 budget chopping block. Although many organizations provide statements about the importance and criticality of the people in their organizations, comments about HR often include 'staff function', 'cost center', 'complaint department', 'the compliance people', and 'the bureaucrats who stop me from managing my employees effectively'". This sentiment is reflected in the increasing proliferation of online HR providers, ready for an organizations' outsourcing of the HR function, with advertising taglines like "BambooHR lets you focus on people, not processes" [2]. HR likes to view itself as strategic to the firm [3], however, HR may be increasingly living in a state of denial and unwilling to accept that such statements may represent a more accurate reflection of the reality of what HR has become, which may be an ossified system that no longer serves its true 'focus on people' purpose effectively [4]. If true, HR may continue to be a ripe target for downsizing and outsourcing efforts in this time of COVID (and post-COVID) budget cuts.

It does not have to be this way, and in fact, it should not if we are to build organizations well-positioned for future competitiveness. If HR is not viewed as strategically central to the functioning of the organization, perhaps it can benefit from this COVID-forced reckoning to undertake a significant self-examination and critical restructuring effort. There may exist some parallels with the logic underlying the "defund the police" movement [5]. As noted by Rashawn Ray in a recent Brookings Institution article, "Defund does not mean abolish policing. Additionally, even some who say abolish, do not necessarily mean to do away with law enforcement altogether. Rather, they want to see the rotten trees of policing chopped down and fresh roots replanted anew" [6]. These include calls to (1) enhance the service component of the jobs of police officers, to reduce the degree to which officers ${ }^{\prime}$ efforts are overburdened by menial tasks that could be more efficiently accomplished through other employees or systems; (2) establish new and more effective approaches to reduce the effects of unconscious (implicit) bias in policing and its outcomes; and (3) embrace and fund solutions to the structural causes (joblessness, poverty, educational inequity) that causes the need for an enhanced police presence. Adapting all three of these 'defund the police' goals (enhancing the service component, eliminating bias, and engaging with structural issues) to an HR context may serve HR well, and a potential pathway to accomplish this is through an embrace of sustainability and the triple bottom line, which is the focus of this essay. 
Goal 1: Embrace HR restructuring. HR engages structural issues, and rebuilds itself through a sustainability lens to connect itself with the health and welfare of its employees and the health of their communities [7]. Climate change is anticipated to cause population displacement, supply chain disruptions, and raw material supply and price volatility risks for business. The recognition of the need for sustainability is best illustrated by recent high-profile statements, once may have been considered alarmist, which are now mainstream. In December 2019, the Business Roundtable altered its statement on the purpose of a corporation to include "We respect the people in our communities and protect the environment by embracing sustainable practices across our businesses" [8]. According to KPMG's Global CEO Outlook (2019), over three-quarters of CEOs (76\%) say that their organization's growth will depend on their ability to navigate the shift to a low-carbon, clean-technology economy [9]. Additionally, Blackrock's CEO, Larry Fink, said in January of this year that his firm would avoid investments in companies that "present a high sustainability-related risk" and that "awareness is rapidly changing, and I believe we are on the edge of a fundamental reshaping of finance" [10]. A defunded HR would take a similar approach, in terms of reassessing its core assumptions and rebuilding itself to strategically connect the firm to the outside world and revolutionize organizations from within to provide the innovation and creativity needed to face the daunting intertwined environmental and social grand challenges (noted by George et al.) that lie ahead [11]. As organizations transition from this singular profit-based motivation to a multi-stakeholder triple bottom line (TBL) business model (measuring three "bottom lines" - economic, environmental, and societal) [12], a large scale and systematic shift is needed in an organization's systems and processes to reflect this fundamental change in a firm' s mission and orientation. HR is well positioned to accomplish this, as it is embedded in all of the business functions that need to be harnessed (building sustainability into recruitment, selection, training, performance assessment, and compensation/benefits) so that the TBL is meaningful for all employees and can be effective (Stahl et al.) [13]. HR Skills, processes, and tools need to be developed by HR to assist leadership and employees to successfully manage conflict between TBL goals, and to build new cultural values and attitudes. To accomplish this, Cohen et al. [14] suggests that HR should strategically partner with line managers on design and implementation, engage with internal and external stakeholders to find win-win outcomes, and align sustainability principles into organizational cultures. Figure 1 provides a visual depiction of a restructured Sustainable HR function that addresses these concerns.

Goal 2: An enhanced service component of HR, reducing time and effort spent on menial tasks with an enhanced focus on strategic contributions. The degree and rapidity of the shift towards outsourcing the HR function is indicative of a whole system that needs renewal and reform. Any HR functions that have become routinized, should be defunded and outsourced. A rebuilt and streamlined sustainable HR department would harness systems and design-thinking oriented new approaches to operations, product design, and stakeholder engagement to re-connect the firm to innovation. Enhanced usage of data analytics and science-based tools should be engaged to inform and guide decisions, but not to make the decisions themselves. HR managers who lack strategic vision, with a propensity to manage by spreadsheet, would be retrained or replace, otherwise they impede TBL change and reinforce the status quo. The overriding goal would be to rebuild HR to create competitive advantage that mutually benefits the firm and a broader set of stakeholders. Finally, HR should be audited for its strategic sustainability contribution across the organization's value chain to ensure accountability and performance. A defunded and rebuilt HR would be strategic and service-oriented, and function to revolutionize firms from within and enhance connections with external stakeholders to face the daunting challenges that lie ahead.

Goal 3: Establishment of new and more effective approaches to reduce the effects of unconscious (implicit) bias and discrimination in organizations. Values and culture fit have been inadvertently used in the past as a means to exclude people and suppress 
diversity in organizations. The elusive criteria of "fit" is ubiquitous in interviews and as a criterion for promotions, allowing for an implicit similar-to-me bias to creep into organizational decision-making and suppress diversity. Employee referral programs also function to suppress diversity in recruitment, as most people lack diversity in their social circles. Finally, cronyism can creep in, whereby suspect justifications are provided for hiring decisions based on friendship bias, advancing a less qualified and less diverse pool. More objective and scientific data-driven approaches to recruitment, selection, and promotion need to be embraced by a rebuilt HR to reduce subjective decision-making prone to such biases. These tools have existed for years, and yet are rarely used. It has been frustrating to see this again and again as a researcher and consultant in the field. If needed, outsourcing these decisions to external vendors may be necessary to enhance the objectivity and diversity outcomes.

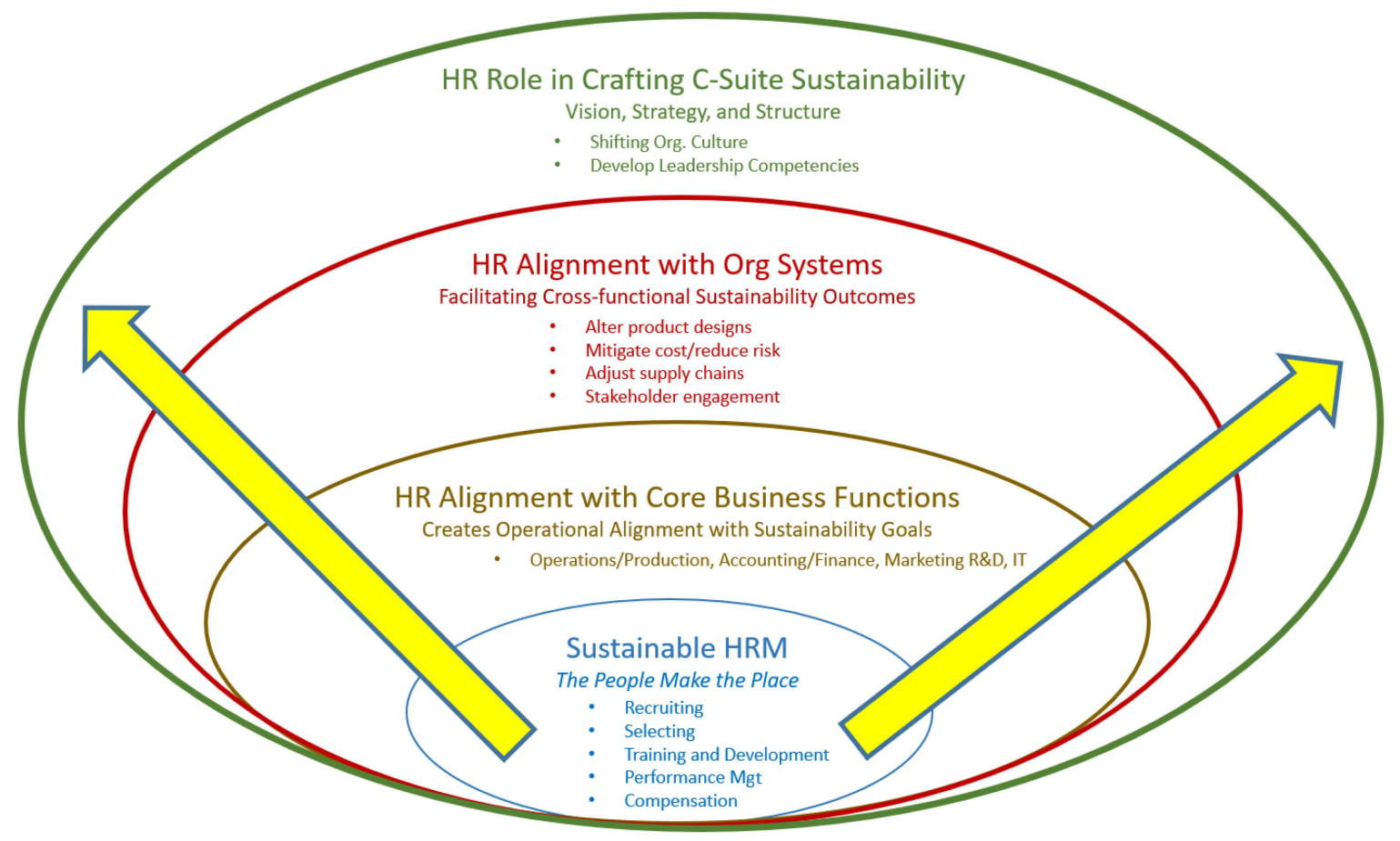

Figure 1. Restructuring Human Resource Management towards Sustainability.

Tactically speaking, once HR is COVID "defunded", what specific steps can be taken to rebuild an HR department that is sustainable? Here is a suggestion for ten steps that organizations could follow:

Step 1: Start with the basics. Efforts begin with helping the C-suite leadership of a firm develop a sustainability vision and strategy. HR can provide critical training opportunities for top executives on sustainability, sustainable business models (industry-specific preferred), and the triple bottom line, either developed in-house or outsourced. HR can also facilitate the engagement of internal and external stakeholders (suppliers, employees, NGOs, communities at home and abroad) in developing a comprehensive and holistic vision and strategy as needed.

Step 2: HR should assist in formalizing the sustainability commitment of top leadership by assisting in the creation of and implementation of a structure, and also in designating the key employees necessary to lead the sustainability mission. For example, Proctor \& Gamble created a cross-functional, broadly representative sustainability leadership council composed of managers from their Global Business Units. Some (perhaps smaller) organizations prefer the simplicity of choosing a single sustainability coordinator, manager, or chief officer as part of a sustainability function. If a HR department is successful at integrating sustainability into its core values and processes, a Sustainable HR leader may be preferable 
for this C-Suite role. Regardless, HR should help ensure that any structure be integrated into C-suite decision-making, and possess the needed training, support staff, and budget (which signals the sustainability priorities of the firm's leaders).

Step 3: HR should select the set of HR policies and practices that most closely align with the specific sustainability outcomes desired by the firm. This may include a focus on a firm's operations-mitigating cost or reducing risk (careful scrutiny of production processes to find ways to decrease inputs or usage of detrimental materials, or adjusting safety routines); product design—altering or replacing current products/services with more environmentally or socially friendly ones (which leads to employee innovation and design-thinking efforts and successfully aligning efforts horizontally across the different functions of the company); and supply chain and stakeholder engagement-determining the breadth of the effort in engaging your supply chain and a broader set of social and environmental stakeholders to achieve TBL goals. HR systems need to be reconfigured to strategically address these sustainability priorities and outcomes. Further, as organizations instill the triple bottom line, HR will need to provide support and training for employees who will be dealing with role ambiguity and conflict. Employees will be grappling with conflicting TBL goals and demands from multiple stakeholders with limited time and resources, and HR can provide the tools, resources, and strategies for employees to find and create synergies or manage priorities and tradeoffs amongst sometimes divergent or conflicting goals.

Step 4: Build a supportive organizational culture. HR develops, leverages, and communicates sustainability-related slogans, rituals, and stories to create and maintain a culture of sustainability, linked to the firm's values and priorities. An example of this is Interface, a carpet manufacturer in Georgia, where David Oakey, Interface's lead designer, reflecting a number of employees who felt overwhelmed when confronted with the CEO's (Ray Anderson) challenge to make carpet that was recyclable and itself made of recycled materials, by saying, "Boss, it can't be done" [15]. Interface is net positive today, and that story is repeated in the firm to help articulate how a sustainability culture creates value for an organization, and to help employees emphasize a culture of challenge, creativity, and continuous improvement. This includes developing effective TBL leadership skills and capabilities across all levels of the organization to recognize and adapt to the inevitable paradoxical tensions that occur, training and development towards cultivating problemsolving and communication skills in resolving and transmitting new approaches and solutions, and techniques to build the engagement of all employees in a TBL-oriented organizational culture.

Step 5: Create line-manager alignment. HR helps line managers grasp the business rationale for sustainability through training, ensuring they each have clearly articulated, measurable sustainability goals built into their job expectations, and that they are held accountable for their goal accomplishment so they can function as role models.

Step 6: Recruit and select new employees including sustainability as a core criterion. HR develops organization-specific recruitment and selection tools and processes to build the sustainability values into the organization's staffing function, for implementation across the breadth of the firm. This will also enhance the human capital of the firm, as the most skilled individuals are attracted to firms with reputations for being sustainable. As employees connect and experience the organization's sustainability efforts, it establishes a psychological contract where employees reciprocate the organization's engagement in the cause with enhanced attitudes and effort to the organization, while also improving employee retention.

Step 7: HR develops onboarding, orientation, and training materials and processes to effectively communicate why and how sustainability and the TBL is meaningful to the organization's mission, strategy, and to their specific jobs. Making a clear business case for sustainability is important. Identify competencies (KSAO's—-knowledge, skills, abilities, and other characteristics) needed in the organization (design thinking, product life cycle analysis, etc.) and address them. 
Step 8: Performance management processes are revised to build the TBL social and environmental outcomes into employee performance appraisals in a manner conducive to measurement (i.e., they should be specific, measurable, realistic, and time constrained). Provide substantive, not token, rewards and recognition to reinforce their importance and achieve enhanced employee motivation.

Step 9: Emphasize employee well-being. HR ensures that sustainability takes root at home in organizations, and leads by example by treating their employees in a socially just manner. If they do not, they risk undermining the credibility of their sustainability values in emphasizing the material but not the human benefits of TBL efforts. Sustainable HRM systems should engender the long-term physical, social, and economic well-being of their firm's workforce (safety, employee involvement/engagement, pay and benefits, freedom from toxins, healthy food, reduced commuting time, examine firm data analytics on employee mortality/morbidity, work hours, work-family conflict, work stress/job design, health care, and addressing inequality).

Step 10: Report on TBL outcomes. What gets measured gets done in organizations. HR can ensure that progress towards the accomplishment of sustainability goals and metrics is widely known, successes are celebrated, strategies are developed for shortcomings, and goals are created for continuous improvement. Reporting on outcomes should transcend the traditional firm level sustainability reporting to measure progress at the functional, department, and individual employee levels. The use of external auditing is recommended to ensure the veracity of the sustainability reporting. Additionally, an enhanced use of data analytics may be a useful tool to assist HR and the organization with information to drive insights to close-the-loop on sustainability goal setting in regard to continuous improvement in the organization's processes, systems, and procedures.

The goal of sustainable HRM is the transformation of HR so that it is fully engaged with the organization's sustainability strategy, building an organization's sustainability capabilities through its core functions of selecting, training, and motivating employees (as indicated in Figure 2). By embracing the complexity of TBL goals through training and development, a sustainable HRM department creates a more knowledgeable, creative, and innovation-focused workforce. Through enhanced engagement with the community and confronting environmental challenges, the firm builds a dedicated and committed workforce, who feel more connected to their employer because they believe in its values.

Sustainable Org Strategy (TBL)

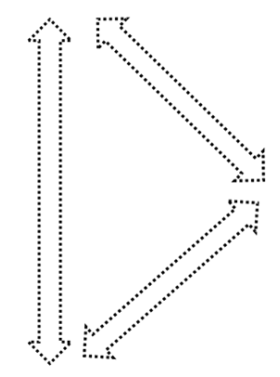

Sustainable HRM
Builds Org. Capabilities

- Innovation

- Resilience

- Ability to Address Paradoxes/Tradeoffs

\& Multiple Goals Simultaneously

- Cope w/Role Ambiguity \& Role Conflict

- Multi-stakeholder Communication Skills

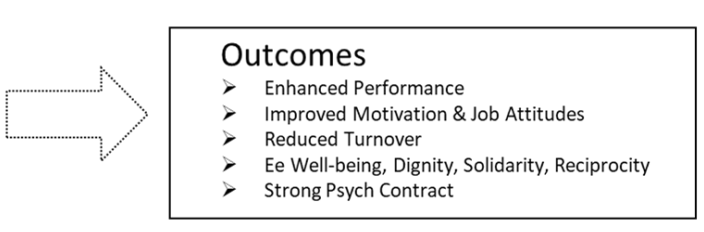

Reduced Turnover

Strong Psych Contract

Figure 2. Building Organizational Capabilities in Sustainable HR.

This is not to downplay the significant challenges that exist in implementing sustainable HRM. Any significant change creates resistance. If you do not have the support of top leadership in a substantive way, any meaningful change is likely to fail. As any organization makes the transition, there will be short-term pain, friction, and conflict, as some employees unwilling to adopt the new cultural attitudes or unable to learn the needed skill sets are retrained or replaced. The TBL goals can also conflict with one another, 
creating difficult choices and tradeoffs between important goals for employees to reconcile, adding significant complexity to employee decision-making [16]. In addition to creating tools, processes, and skills for employees to successfully manage conflicting TBL goals, $\mathrm{HR}$ will be challenged to create new, more flexible approaches to employee performance assessment and compensation that reflect goal tradeoffs. For sustainable HRM to have impact, firm-specific measurement instruments and practices also need to be developed and tested to help firms recruit, select, train and develop employees. Finally, values and culture fit have been used in the past as a means to exclude people and suppress diversity in organizations. As sustainability can be viewed as a luxury of the privileged, its social justice aspects need to be understood, illuminated, and leveraged to enhance, not reduce diversity. However, a new cadre of CEOs and business leaders is coming onto the scene who view the role of business more broadly, as not solely beholden to shareholders. A return to HR's 'personnel department' roots, with a focus on community integration connections, a back-to-the-future perspective, seems increasingly necessary. To accomplish the transition of an organization to better include the TBL of serving the community and its environment, a COVID-forced, defunded and rebuilt HR function may serve as the strategic lynchpin for these efforts.

Funding: This research received no external funding.

Institutional Review Board Statement: Not applicable.

Informed Consent Statement: Not applicable.

Data Availability Statement: Not applicable.

Conflicts of Interest: The author declares no conflict of interest.

\section{References}

1. Gartner, Inc. Gartner Reveals Best Practices to Drive HR Cost Optimization During Coronavirus. 2020. Available online: https: //www.gartner.com/en/newsroom/press-releases/2020-03-30-gartner-reveals-best-practices-to-drive-hr-cost-optim (accessed on 10 September 2020).

2. Bamboo. Bamboo HR. 2020. Available online: https://www.bamboohr.com/g/optim (accessed on 10 September 2020).

3. Jamrog, J.; Overholt, M. Building a Strategic HR Function: Continuing the Evolution. Hum. Resour. Plan. 2020, $27,51-62$.

4. Crisp, D. HR must be the model of good leadership or risk being irrelevant. Can. HR Report. 2002, 15, $19-23$.

5. Defund the Police. Available online: https://defundthepolice.org/ (accessed on 10 September 2020).

6. Ray, R. What Does Defund the Police Mean, and Does It Have Merit? Brookings Institution. Available online: https://www. brookings.edu/blog/fixgov/2020/06/19/what-does-defund-the-police-mean-and-does-it-have-merit/ (accessed on 10 September 2020).

7. Westerman, J.; Rao, M.B.; Vanka, S.; Gupta, M. Sustainable human resource management and the triple bottom line: Multistakeholder strategies, concepts, and engagement. Hum. Resour. Manag. Rev. 2020, 30, 100742. [CrossRef]

8. Business Roundtable. Business Roundtable Redefines the Purpose of a Corporation to Promote 'An Economy That Serves All Americans'. 2019. Available online: https:/ / www.businessroundtable.org/business-roundtable-redefines-the-purpose-of-acorporation-to-promote-an-economy-that-serves-all-americans (accessed on 10 September 2020).

9. KPMG. KPMG's Global CEO Outlook: CEOs Name Climate Change as \#1 Risk to Organizational Growth. 23 September 2019. Available online: https://home.kpmg/us/en/home/media/press-releases/2019/09/ceos-name-climate-change-as-1-risk-toorganizational-growth.html (accessed on 10 September 2020).

10. Blackrock. A Fundamental Reshaping of Finance. 2020. Available online: https://www.blackrock.com/uk/individual/larryfink-ceo-letter (accessed on 10 September 2020).

11. George, G.; Howard-Grenville, J.; Joshi, A.; Tihanyi, L. Understanding and tackling societal grand challenges through management research. Acad. Manag. J. 2016, 59, 1880-1895. [CrossRef]

12. Elkington, J. Cannibals with Forks: The Triple Bottom Line of Twentieth Century Business; Wiley: New York, NY, USA, 1997.

13. Stahl, G.K.; Brewster, C.J.; Collings, D.G.; Hairo, A. Enhancing the role of human resource management in corporate sustainability and social responsibility: A multi-stakeholder, multidimensional approach to HRM. Hum. Resour. Manag. Rev. 2020, $30,100708$. [CrossRef]

14. Cohen, E.; Taylor, S.; Muller-Camen, M. HRM's role in corporate social and environmental sustainability. SHRM Rep. 2012, 1, 1-16. Available online: https:/ / www.shrm.org/hr-today/trends-and-forecasting/special-reports-and-expert-views/Documents / Corporate-Social-Environmental-Sustainability.pdf (accessed on 16 June 2021). 
15. Lovins, H. How Interface Realized That the Carpet Business as Usual Wasn't Sustainable. Greenbiz. 2018. Available online: https: //www.greenbiz.com/article/how-interface-realized-carpet-business-usual-wasnt-sustainable (accessed on 10 September 2020).

16. Podgorodnichenko, N.; Edgar, F.; McAndrew, I. The role of HRM in developing sustainable organizations: Contemporary challenges and contradictions. Hum. Resour. Manag. Rev. 2020, 30, 100685. [CrossRef] 